\title{
CENTRO DE TECNOLOGIA ACADÊMICA DA UFRGS COMO COMUNIDADE DE PRÁTICA E POSSIBILIDADE DE CRIAÇÃO DE ESPAC̣OS NÃO FORMAIS DE APRENDIZAGEM: UM ESTUDO ETNOGRÁFICO
}

\author{
DANIEL FARIAS MEGA ${ }^{*}$ \\ https://orcid.org/0000-0002-1233-5903 \\ IVES SOLANO ARAUJOI"** \\ https://orcid.org/0000-0002-3729-0895 \\ ELIANE ANGELA VEIT ${ }^{1 * * *}$ \\ https://orcid.org/0000-0002-2406-3415
}

RESUMO: A promoção de autênticas experiências de aprendizagem na formação discente é um desafio para a maior parte das instituições de ensino. A busca por iniciativas já em andamento que possam contribuir para alcançar este objetivo pode revelar possibilidades de ações futuras. No presente trabalho apresentamos os resultados de um estudo etnográfico no Centro de Tecnologia Acadêmica da UFRGS. Entendemos que seu modelo de gestão de conhecimento pode servir para o cultivo de ambientes não formais de aprendizagem. Como resultado, pudemos tipificar o CTA como uma Comunidade de Prática, identificando seus elementos estruturais. Tal caracterização pode inspirar a criação de centros similares em outras instituições de ensino, auxiliando, assim, profissionais interessados em ampliar as oportunidades formativas de seus estudantes.

Palavras-chave: Comunidades de Prática. Ambientes não formais de aprendizagem. Ensino de Física.

\section{CENTRO DE TECNOLOGÍA ACADÉMICA DE UFRGS COMO COMUNIDAD DE PRÁCTICA Y POSIBILIDAD DE CREACIÓN DE ESPACIOS NO FORMALES DE APRENDIZAJE: UN ESTUDIO ETNOGRÁFICO}

RESUMEN: Proporcionar auténticas experiencias de aprendizaje en la capacitación de los estudiantes es un desafío para muchas instituciones educativas. La búsqueda de iniciativas en curso que puedan contribuir a lograr este objetivo puede exponer posibilidades para

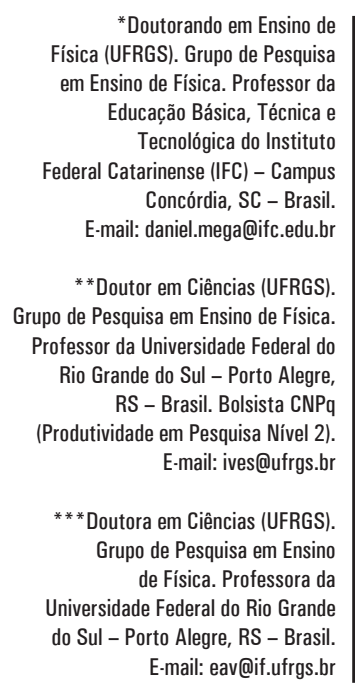

I Instituto Federal Catarinense, Concórdia, SC - Brasil.

II Universidade Federal do Rio Grande do Sul, Porto Alegre, RS - Brasil. 
acciones futuras. En este trabajo presentamos los resultados de un estudio etnográfico en el Centro de Tecnología Académica de UFRGS (Universidade Federal do Rio Grande do Sul). Suponemos que su modelo de gestión del conocimiento se puede utilizar para fomentar espacios no formales de aprendizaje. Como resultado, pudimos caracterizar el CTA como una comunidad de práctica, identificando sus elementos estructurales. Esta caracterización puede inspirar la creación de centros similares en otras instituciones de enseñanza, lo que ayudaría a los profesionales interesados en ampliar las oportunidades de capacitación para sus estudiantes.

Palabras clave: Comunidades de Práctica. Espacios no formales de aprendizaje. Enseñanza de la Física.

\section{ACADEMIC TECHNOLOGY CENTER OF UFRGS AS A COMMUNITY OF PRACTICE AND POSSIBILITY OF CREATION OF NON-FORMAL LEARNING SPACES: AN ETHNOGRAPHIC STUDY}

ABSTRACT: Provide authentic learning experiences in the training of students is a challenge for many educational institutions. The search for ongoing initiatives that can contribute to achieving this objective may expose possibilities for future actions. In this work we present the results of an ethnographic study in a Center of Academic Technology of a Brazilian public university. We assume that its knowledge management model can be used to foster non-formal learning spaces. As a result, we were able to typify it as a community of practice, identifying its structural elements. This characterization can inspire the creation of similar centers in other teaching institutions, assisting professionals interested in expanding the training opportunities for their students.

Keywords: Community of practice;. Non-formal learning spaces. Physics education. 


\section{INTRODUÇÃO}

Inovar, pensar criticamente, resolver problemas, tomar decisões, trabalhar de maneira colaborativa e viver no mundo com responsabilidade social e ambiental são comumente listadas como competências necessárias para o cidadão do século XXI (BINKLEY et al., 2012). No entanto, como afirma Moreira (2017), a educação contemporânea, desatualizada, centrada na figura do professor, e focada em treinar os alunos para realização de provas, pouco contribui para as necessidades formativas atuais. Encontrar caminhos para a promoção de oportunidades de aprendizagem e desenvolvimento de habilidades de forma mais autêntica por parte dos alunos, e sem que isso signifique sobrecarregar ainda mais o currículo dos cursos de formação, se mostra um desafio para os sistemas educativos contemporâneos.

Uma via possível para o enfrentamento desses problemas, passa por estimular o desenvolvimento de espaços não formais de aprendizagem. De acordo com Castro (2015, p. 172)

atualmente, essa expressão [espaços não formais de aprendizagem] designa não só as atividades complementares ao currículo escolar, realizadas na escola ou fora dela, mas também aquelas que ocorrem em outros espaços, de forma independente dos conteúdos escolares ou a eles associados, embora com objetivos diversos.

Os espaços não formais de aprendizagem proporcionam o compartilhamento de experiências em ações cotidianas, caracterizadas pela intencionalidade no fazer. Por exemplo, filiar-se voluntariamente a um clube de ciências em uma escola é uma intencionalidade, uma vez que o aluno tem um desejo, toma a decisão de realizar as atividades propostas e busca os caminhos para isso. Segundo Gohn (2016), as principais características de tais espaços são: (i) existe intencionalidade na ação dos participantes, no ato de aprender e de trocar saberes; (ii) não há organização por séries, idades e conteúdo; (iii) são desenvolvidos laços de pertencimento, auxiliando a construção de identidade coletiva de grupos e (iv) são estruturados pela identificação de um interesse em comum.

Nessa perspectiva podem ser enquadradas as Comunidades de Prática ${ }^{1}(\mathrm{CoP})$, vistas como estruturas sociais que possuem a prática como fonte de coerência de sua unidade e se caracterizam pela existência de um empreendimento comum, um compromisso mútuo entre os participantes e um repertório de falas e atitudes compartilhados. Um grupo de programadores pode configurar uma CoP quando se engajam em empreender o desenvolvimento de softwares e à medida que compartilham essa prática negociando significados, aprendem e fazem com que a comunidade avance no seu domínio de conhecimento.

No presente trabalho investigamos o Centro de Tecnologia Acadêmica da Universidade Federal do Rio Grande do Sul, um laboratório de criação e experimentação de tecnologias. Nossa investigação busca avaliar de que forma ele se configura, caso se configure, como um espaço dessa natureza.

Por se tratar de uma iniciativa local, reconstruir seu modelo de gestão de conhecimento, suas práticas, métodos e princípios em outros contextos educacionais requer cautela e se mostra um grande desafio. Para isto é importante caracterizá-lo a 
partir de um referencial teórico consistente, capaz de tornar possível a compreensão e interpretação das dinâmicas internas que ocorrem no Centro.

Por esse motivo fizemos uso do conceito de Comunidades de Prática, proposto pelos pesquisadores Jean Lave e Etienne Wenger no final da década de 1980. Os autores definem essas organizações como grupos de pessoas que mostram interesse sobre determinado tópico, e que aprofundam seu conhecimento e especialização nessa área pela interação contínua (LAVE e WENGER, 1991). Contudo, de acordo com Wenger (2001, p. 157-158), considerar qualquer configuração social como uma Comunidade de Prática torna o conceito sem sentido e "pode induzir a erros" uma vez que seria fácil ignorar a multiplicidade e as perspectivas envolvidas nesses grupos.

Durante um ano foram observadas e interpretadas as práticas do CTA, suas relações, comportamentos interpessoais, suas crenças e visões de mundo, suas produções materiais, suas tradições e histórias compartilhadas, de maneira a tornar possível a busca de respostas à seguinte questão de pesquisa: Qual é o retrato cultural do CTA e em que medida ele pode ser considerado uma Comunidade de Prática?

Para atingir esse fim, realizamos uma pesquisa qualitativa do tipo etnográfico. Segundo Angrosino (2009, p. 30) "a etnografia é a arte e a ciência de descrever um grupo humano - suas instituições, seus comportamentos interpessoais, suas produções materiais e suas crenças." As características centrais do método etnográfico são a condução da pesquisa no local em que as pessoas atuam e desenvolvem sua cultura, e o compromisso de longo prazo, ou seja, o pesquisador interage com as pessoas que compartilham essa cultura durante um longo período. Como afirma Creswell (2014, p. 82):

a etnografia envolve observações ampliadas do grupo, mais frequentemente por meio da observação participante, em que o pesquisador mergulha nas vidas diárias das pessoas e observa e entrevista os participantes do grupo.

Salientamos que este estudo faz parte de um projeto mais amplo, que visa propor diretrizes para o fomento e criação de centros de aprendizagem colaborativa, de natureza não formal para o ensino de Física.

\section{REFERENCIAL TEÓRICO}

É comum supor que a aprendizagem se baseia em processos individuais e que seu sucesso depende exclusivamente dos métodos de ensino utilizados. Wenger (2001) propõe que olhemos para a aprendizagem como uma característica inerente ao ser humano, que decorre das nossas experiências de participação no mundo.

$\mathrm{O}$ autor entende que a natureza da relação entre o conhecimento, o conhecer e os conhecedores pode ser resumida em quatro premissas (ibid., p. 21):

1) O fato de sermos seres sociais é um aspecto essencial da aprendizagem.

2) O conhecimento é uma questão de aptidão para certos empreendimentos que valorizamos.

3) Conhecer é participar, de maneira ativa, na realização desses empreendimentos. 
4) O significado - nossa habilidade de experimentar o mundo como algo significativo - é, em última instância o que a aprendizagem deve produzir.

Desta forma o aspecto central da teoria é a aprendizagem como participação social. A participação é entendida como um processo ativo nas práticas de comunidades sociais, onde são construídas identidades relativas a essas comunidades. Sob essa óptica a participação social nesses grupos e o ato de aprender se dá através da inter-relação de quatro elementos: o significado, a prática, a comunidade e a identidade. Sobre esses componentes Wenger (2001, p. 22) considera que significado é a capacidade humana de experimentar a vida e o mundo como algo significativo; prática são maneiras de falar dos recursos históricos e sociais, das perspectivas compartilhadas que podem sustentar o compromisso mútuo na ação; comunidade são configurações sociais, onde realizamos empreendimentos/ tarefas que definimos como valiosas e identidade é mudança pessoal acarretada pela aprendizagem no contexto de nossas comunidades.

Nessa perspectiva existe uma forte associação entre aprendizagem e identidade. No entanto, o formato tradicional de aula, amplamente utilizado no ensino formal, muitas vezes desconexo da realidade e uniformizado, não permite que os alunos vivenciem experiências que apoiem significativamente sua identificação. De acordo com Wenger (2001, p. 317, tradução nossa) ele "oferece pouca textura para negociar identidades: um professor que se sobressai e um grupo homogêneo de estudantes que aprendem a mesma coisa ao mesmo tempo". Nesse contexto, ser competente significa: agradar o professor, acabar as tarefas antes dos demais e obter boas notas nas avaliações. Por outro lado, as CoP possibilitam que o projeto educativo não se dê apenas em função de um currículo engessado, mas sim em termos de formação de uma identidade de aprendizagem. Esses espaços fornecem lugares de participação, experiências e materiais que proporcionam aos alunos uma visão mais ampla do mundo e de si mesmos de maneira que suas ações tenham importância social.

A estrutura básica de uma Comunidade de Prática é composta por três elementos fundamentais, o domínio, a prática e a comunidade (WENGER, MCDERMOTT e SNYDER, 2002).

Em linhas gerais o domínio pode ser entendido como os temas chave que dão à comunidade uma identidade própria, ou seja, ele é a razão de ser da Comunidade de Prática. Por consequência, o domínio permite distinguir os membros da comunidade de outras pessoas. Ele não é um elemento estático, se modifica à medida que a comunidade evolui. Novos membros podem trazer inovações ao domínio, por exemplo, o de uma comunidade de programadores de computador se modifica cada vez que uma nova linguagem de programação ou mesmo novos hardwares surgem.

Já os conceitos de comunidade e de prática se especificam mutuamente e a expressão Comunidade de Prática (WENGER, 2001) deve ser entendida como uma unidade. $\mathrm{O}$ autor entende que a união desses termos produz uma caracterização mais maleável do conceito de prática diferenciando-o de termos como cultura e atividade. Além disso essa associação define um tipo especial de comunidade, as Comunidades de Prática. Essa união está fundamentada em três dimensões que fazem com que a 
prática seja a fonte de coerência de uma comunidade (WENGER, 2001, p. 100), são elas: o compromisso mútuo, o empreendimento conjunto e o repertório compartilhado.

Participar de maneira ativa de uma Comunidade de Prática demanda que o sujeito se comprometa com os outros membros, respondendo pelas ações que realiza dentro da comunidade. Essa reciprocidade se torna a base para a criação de uma identidade de participação e de um sentimento de pertencimento à comunidade.

$\mathrm{O}$ autor destaca que

o compromisso mútuo não supõe homogeneidade, mas cria relações entre as pessoas. Quando se mantém, conecta os participantes de maneiras que podem ser mais profundas que outras similares e mais abstratas expressadas em função de características pessoais ou categorias sociais. Neste sentido, uma Comunidade de Prática pode se converter em um núcleo muito firme de relações interpessoais. (WENGER, 2001, p. 104, tradução nossa)

Pode ser que os programadores do exemplo anterior se engajem no desenvolvimento de softwares livres fazendo isso por uma paixão, um interesse em contribuir com outros desenvolvedores e não meramente por um ganho financeiro. Quando escolhem se engajar nesse empreendimento criam intensas relações de participação mútua que são mantidas pela prática utilizada para levar adiante esse esforço. ${ }^{2}$

O empreendimento conjunto é algo que cria entre os participantes vínculos de compromisso mútuo, convertendo-se em uma parte integral da prática. Esta dimensão mantém a Comunidade de Prática unida e é resultado de um processo coletivo de negociação.

Negociar um empreendimento conjunto dá origem a algumas relações de responsabilidade mútua entre os envolvidos. Estas relações incluem o que importa e o que não, o que é importante e porque é, o que fazer e o que não fazer, no que prestar atenção e no que não, do que falar e do que não, o que justificar e o que dar por certo, o que mostrar e o que ocultar, quando algumas ações e alguns artefatos são bons e quando devem ser melhorados. (WENGER, 2001, p. 108, tradução nossa)

A última característica da prática que funciona como agregadora da comunidade é o desenvolvimento de um repertório compartilhado. Ele inclui rotinas, expressões, instrumentos, maneiras de fazer, símbolos e gestos. À medida que os programadores vão desenvolvendo e amadurecendo seus projetos, criam recursos para que possam negociar significados. A construção desse repertório permite que a comunidade lide com o seu domínio de maneira mais eficiente.

Apoiado nessas três dimensões, Wenger (2001, p. 125) afirma que "as práticas são histórias de um compromisso mútuo, de uma negociação de um empreendimento e de um desenvolvimento de um repertório compartilhado." 
Portanto, investigar em que medida o CTA pode ser considerado uma CoP é uma iniciativa importante para o entendimento dos processos de aprendizagem decorrente das práticas que realizam. Além disso, permitirá a realização de estudos que proponham diretrizes para incentivar a criação de espaços que adotem seu modelo de gestão de conhecimento em outros ambientes escolares.

\section{METODOLOGIA}

Nesta seção apontamos os caminhos metodológicos trilhados para o desenvolvimento deste trabalho. Primeiramente (Seção a) apresentamos o terreno de estudo, esclarecemos que as informações que constam nessa subseção foram coletadas durante o desenvolvido do estudo, por meio de pesquisas documentais e observação participante. Em seguida nas Seções b e c apresentamos os procedimentos utilizados para a coleta e análise de dados, respectivamente. Salientamos, também, que o primeiro autor do trabalho atuou como observador participante nas atividades realizadas no CTA e realizou o estudo etnográfico narrado na sequência. Por isso, no relato do estudo é utilizada a primeira pessoa do singular.

\section{a. Terreno de estudo}

O nascimento do CTA já começa com um processo negociado. Fundado em 2012 por um grupo de 16 pessoas formado por professores e alunos da UFRGS o CTA almejava a construção de um espaço capaz de "resgatar o papel da universidade como local de domínio e cultivo do saber humano". 3 Para que isso fosse possível seus fundadores conjecturaram que a utilização e desenvolvimento de tecnologias livres, isto é, sujeitas à liberdade de uso, estudo, modificação e distribuição, garantiria a autonomia tanto do uso como do estudo dessas tecnologias. A ideia era fomentar a criação de um espaço que fosse na contramão das práticas de ensino tradicionais amplamente utilizadas nas salas de aula da universidade e que permitisse garantir ao aluno a autonomia no aprendizado. O grupo atua no desenvolvimento de instrumentos científicos educacionais utilizando software livre e disponibiliza toda a sua criação em repositórios públicos sob termos de licenças permissivas. O desenvolvimento de projetos é baseado no conceito de Hiperobjeto, uma classe de objetos localizada na intersecção entre software livre, hardware livre e documentação livre (Figura 1). 
Figura 1. Hiperobjeto

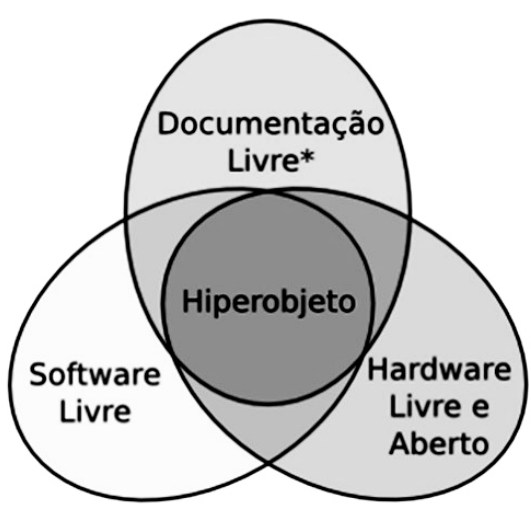

Fonte: PEZZI et al., 2017

Dito de outra forma, é um objeto desenvolvido com ferramentas livres, utilizado com software livre e que tenha documentação livre.

A documentação livre engloba todo o material multimídia acerca do objeto que esteja disponível sob os termos de licenças permissivas e formatos abertos, idealmente construída com software livre. Ela pode incluir também manuais de uso, guias de atividades e aplicações em contextos de educação e ciência. Isto é, a documentação integra ao hiperobjeto todo o material produzido relacionado a ele que foi disponibilizado em conformidade com as definições de obras culturais livres e de conhecimento aberto. (PEZZI et al., 2017, p. 213)

Exemplos de hiperobjetos são a impressora 3D RepRap, ${ }^{4}$ projeto desenvolvido na escola de engenharia da Universidade de Bath na Inglaterra e as Estações Meteorológicas Modulares de Código Aberto, ${ }^{5}$ desenvolvido pelo próprio CTA.

Uma importante característica das práticas realizadas no CTA é que não existe um dia típico. Determinadas situações ocorrem com mais frequência que outras, dependendo da época do ano. É comum que em alguns dias ninguém vá ao laboratório, mas também é comum que em outros ele fique lotado de colaboradores desenvolvendo Hiperobjetos.

\section{b. Procedimento para a coleta de dados}

Entre setembro de 2017 e agosto de 2018, realizei imersão para um estudo etnográfico que teve início com a participação nos encontros semanais realizados no laboratório. Durante esse período, ocorreram 20 reuniões semanais totalizando a participação de 45 pessoas, a média por reunião foi de 10 presentes. Sua maioria $(\sim 6 / 10)$ alunos do curso de Engenharia Física, mas também participavam professores e alunos de licenciaturas e bacharelados em Física, Matemática e outras 
engenharias, tais como Elétrica e da Computação. Destas 45 pessoas, destacamos a participação mais assídua de quatro colaboradores, o professor coordenador do laboratório e três alunos que formavam o núcleo central da CoP. Segundo Wenger e Trayner (2015) em muitas CoP, é indispensável tomar decisões e organizar determinadas situações, mas nem todos os membros valorizam o envolvimento nesses processos. Independentemente da denominação que recebem, líderes, coordenadores, gestores ou administradores, alguém deve realizar esse papel que é valorizado pela comunidade.

No primeiro encontro semanal que participei explicitei minha intenção em realizar um estudo etnográfico; para isso estabeleci diálogos com os guardiões ${ }^{6}$ do CTA, a fim de obter acesso para realizar minha pesquisa. No início de 2018 me prontifiquei na organização da III Hackatona ${ }^{7}-C T A$, cujo objetivo foi a construção de um relógio que seria fixado no auditório do Instituto de Física da Universidade. $\mathrm{O}$ evento foi realizado em três etapas. A primeira ocorreu nos dias 17 e 18 de março, a segunda nos dias 21 e 22 de abril e a terceira nos dias 02 e 03 de junho. Deste evento participaram 12 pessoas, ainda que tenha sido aberto ao público externo ao CTA, apenas três inscritos tiveram o primeiro contato com o laboratório durante a Hackatona, as demais já eram familiarizadas com as práticas do centro em maior ou menor grau.

Também me envolvi nas reuniões de planejamento e avaliação das três etapas do evento, juntamente com os outros três responsáveis por organizar a Hackatona. Além disso, observei uma oficina introdutória sobre Arduino ${ }^{8}$ ministrada por colaboradores do laboratório.

Durante toda a imersão, assumi o papel de observador participante, auxiliando nas tarefas realizadas pelo grupo, participando de conversas formais e informais face a face e por canais virtuais como e-mails, fóruns e aplicativos de troca de mensagens.

Pude coletar um vasto conjunto de dados essencialmente por meio desse método. Ao total foram coletadas 20 horas de gravações em áudio, 2 horas em vídeo, 240 registros fotográficos e em menor quantidade anotações que realizei no meu diário de campo, por vezes no momento em que ocorriam e por vezes após os fatos observados.

Embora tenha participado das atividades desenvolvidas como um membro do centro, nunca ocultei dos colaboradores meu papel de pesquisador. Todos estavam cientes, desde o princípio que em minha estada no CTA, desenvolveria uma pesquisa de doutorado sobre Comunidades de Prática e que uma das etapas de minha tese seria o estudo da cultura do Centro de Tecnologia Acadêmica.

Ademais, recorri à coleta de informações em documentos disponibilizados no site do CTA veiculados em wikis, fóruns e páginas de projetos. Também foram coletados e-mails, trocados em listas de discussão nos grupos do CTA, e conversas que ocorreram via internet em grupos de aplicativos de trocas de mensagens e chats on-line. 


\section{c. Procedimentos para a análise de dados}

A grande quantidade de dados coletados durante a imersão na vida cotidiana do CTA foi organizada em arquivos digitais. Para auxílio dessa tarefa utilizei o software de análise qualitativa de dados NVivo 12. Os arquivos de áudio, vídeo, notas de campo, e-mails, documentos coletados no site e de fotografias foram classificados em pastas, organizadas por tipo e data. Isso permitiu que a narrativa etnográfica produzida se mantivesse fiel quanto à ordem cronológica dos acontecimentos.

Os arquivos de dados brutos, de áudio e vídeo, foram convertidos em unidades de texto. O processo de transcrição permitiu que trechos importantes fossem facilmente localizados e codificados na grande quantidade de dados coletados durante o estudo.

Após essa organização, pude ter uma visão geral de toda base de dados, o que possibilitou um exame detalhado, das transcrições, fotos, notas de campo e outros documentos coletados. Nesse processo busquei padrões de comportamento dos colaboradores do CTA para identificar a cultura e as práticas realizadas no grupo. Como minha intenção foi verificar em que medida o CTA se caracterizava como uma Comunidade de Prática busquei identificar nos dados elementos que explicitassem as três dimensões da prática que dão coerência à comunidade, o compromisso mútuo, o empreendimento conjunto e o repertório compartilhado. Para tal, formei códigos extraídos dos indicadores propostos por Wenger (2001, p. 158-159), portanto preexistentes, para avaliar se uma CoP se formou ou não. Tais indicadores (Quadro 1) são capazes de apontar que as três dimensões da prática estão presentes de maneira considerável. O número de passagens associadas a cada código foi um indicador, mas não relatamos essas contagens tendo em vista que ela

transmite uma orientação quantitativa da magnitude e frequência, que é contrária à pesquisa qualitativa. Além disso, uma contagem transmite a ideia de que todos os códigos devem receber igual ênfase e desconsidera que as passagens codificadas possam na verdade representar visões contraditórias (CRESWELL, 2014, p. 150). 
Quadro 1. Indicadores associados às três dimensões da prática que foram utilizados como códigos na análise de dados.

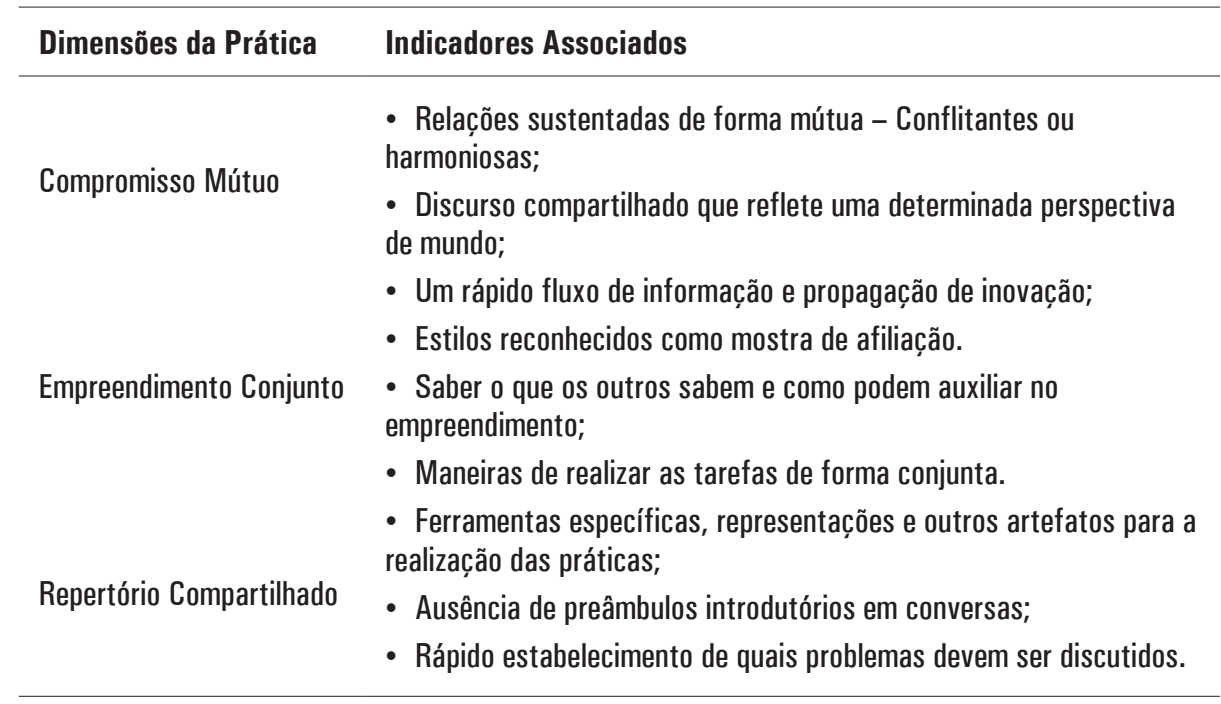

Essa codificação possibilitou identificar padrões de comportamento, ou seja, um comportamento real partilhado pelos membros do grupo, ou que se acredita desejável, legítimo e correto: um comportamento ideal (ANGROSINO, 2009). Tais padrões foram apreendidos essencialmente em declarações públicas coletadas durante a observação participante, uma vez que elas têm maior probabilidade de refletir o comportamento ideal do grupo do que em uma entrevista, por exemplo, e puderam ser triangulados por documentos acessíveis no site do CTA, como atas, fóruns e Wikis, bem como por troca de e-mails e mensagens em chats. Durante minha estada no CTA busquei não provocar reações dos participantes da pesquisa deixando-os agir naturalmente. A triangulação é um procedimento básico na pesquisa etnográfica e central para a sua validade, permite comparar uma fonte de informação com outra para que seja possível descartar explicações e encontrar padrões de comportamento do grupo. Segundo Fetterman (2010, p. 94)

Tipicamente, o etnógrafo compara as fontes de informação para testar a qualidade da informação (e a pessoa que a compartilha), para ter um entendimento mais amplo do papel que um ator desempenha no contexto social e, finalmente, para colocar toda a situação em perspectiva.

A seguir, apresentamos, através de duas narrativas etnográficas os resultados obtidos com a análise dos dados. 


\section{NARRATIVAS ETNOGRÁFICAS}

Para apresentar os resultados de nossa investigação, lanço mão de dois tipos de narrativa etnográfica.

A primeira (Seção a) é uma vinheta narrativa intitulada "Boas Vindas, venham colaborar com o CTA". " Ela busca oferecer ao leitor o contexto da pesquisa, narrando eventos marcantes de uma maneira compactada. Embora apresente um formato literário, é uma construção feita a partir dos dados extraídos da observação participante, documentos e outros instrumentos. Portanto, vários indivíduos participantes da pesquisa são a fonte desses dados. A redação da vinheta é construída através dos padrões de comportamento que emergem dos dados, segundo Erickson (1990, p. 50, tradução nossa) "essa narrativa é analítica - certas características da ação social e do significado são destacadas, outras são apresentadas com menos destaque ou não são mencionadas". Nossa vinheta mostra um dia sob a perspectiva de um personagem fictício composto, que chamei de Duda e que participa do CTA no papel de aluno. A utilização de um personagem fictício composto é incomum, mas não inédito na literatura, alguns exemplos são os trabalhos de Wareing (2010a, 2010b), Humphreys e Brown (2008, apud MANN, 2013) e Mann (2013). Além desses estudos, a principal referência sobre Comunidades de Prática, o trabalho de Wenger (2001), também faz uso de uma vinheta narrativa, onde o ator principal é um personagem compósito.

A segunda narrativa (Seção b), trata-se de um texto em que são apresentados os resultados em um formato mais focado e tradicional, mesmo que ainda empregue formas descritivas e é nessa narrativa que os dados se vinculam fortemente com a literatura.

\section{a. Vinheta Narrativa}

A jornada que narro a seguir, apresenta episódios reais na vida dos colaboradores do CTA. Dou ênfase a eventos representativos e padrões de comportamento (Quadro 1) que puderam ser verificados no processo de análise de dados. Ainda que não tenham sido observadas no mesmo dia, todas as situações que apresento são factuais e ocorreram durante minha imersão nas práticas do C'TA no papel de observador participante, portanto não se trata de invenções disfarçadas como fatos. Essas informações foram coletadas e tratadas através dos procedimentos metodológicos descritos anteriormente e possibilitaram a construção da vinheta.

Procurei dar relevância à linguagem utilizada pelos participantes. Para isso, ao longo do texto encontram-se expressões extraídas de seus discursos, ${ }^{10}$ que aparecem sempre entre aspas e formatadas em itálico, quer para lhe conferir maior destaque, quer para permitir ao leitor distingui-las no meio do texto construído no processo de descrição e interpretação dos dados.

Por questões éticas Duda e todos os personagens que aparecem na narrativa são pseudônimos. A escolha pelo nome Duda foi feita por esse apelido poder se referir tanto a um nome masculino quanto a um nome feminino. No CTA, 
existe uma preocupação com a representatividade de todas as identidades, sejam de gênero, etnia ou outras. Esse fator contribui para a garantia de participação de todas as pessoas, com atenção às suas diferentes condições.

E importante enfatizar novamente a opção por uma vinheta que narra os acontecimentos em um mesmo dia, mesmo que eu os tenha observado em dias diversos. Ela busca auxiliar o leitor na contextualização e no entendimento das práticas desenvolvidas pelo CTA tornando o texto mais compacto e descomplicado.

\section{Boas Vindas, venham colaborar com o CTA}

Quando Duda chega ao campus do Vale e desembarca do ônibus D43 ${ }^{11}$ se dirige ao conjunto de prédios que abrigam o Instituto de Física da UFRGS. No primeiro deles uma pequena placa de plástico, fixada na parede ao lado de um portão azul, identifica o laboratório “Tecnologia com Ciência, 110”. Do outro lado do portão, fixada no chão, uma placa retangular pintada com certo desleixo mostra a sigla CTA e alguns triângulos dispostos por toda a sua superfície. Os quatro triângulos que formam o triângulo maior do logotipo do CTA representam as quatro liberdades de uso das obras culturais livres: ${ }^{12}$ a liberdade de usar, de estudar, de copiar e de modificar a obra em questão. Na parte externa do Laboratório além dos pequenos logotipos no cartaz, não existe escrita alguma que o identifique como "Centro de Tecnologia Acadêmica". Em função disso, aqueles que não conhecem o laboratório passam por ele sem saber o que existe por trás daquele grande portão azul de garagem.

Embora desenvolva projetos no CTA somente há dois anos, Duda pode ser considerado(a) um(a) colaborador(a) ${ }^{13}$ que faz parte do núcleo central do laboratório. Por isso possui as chaves do portão. Quando entra na sala, imediatamente acende os seis conjuntos de luzes que iluminam o ambiente. Mesmo que a manhã esteja ensolarada as estreitas janelas localizadas na parte superior de uma das paredes da sala não fornecem a iluminação natural adequada.

E cedo e talvez, ainda pela manhã, dois ou três outros(as) colaboradores(as) do CTA irão aparecer para trabalhar em seus projetos.

Por se tratarem de alunos(as) de cursos acadêmicos, sua maioria dos cursos de Física, dividem seu tempo na universidade entre as aulas de Cálculo, Física, Estrutura da Matéria, Equações Diferenciais, ... e os projetos extracurriculares que desenvolvem dentro do CTA.

Eles(as) não cumprem horários predeterminados e se vinculam aos projetos e atividades do Laboratório de maneira voluntária e intencional. Alguns(mas), interessados(as) nas horas de atividades complementares necessárias para concluir o curso ou em busca de uma bolsa de estudos outros(as) interessados(as) em aprender eletrônica, programação ou até mesmo trazidos(as) pela influência de colegas que já participam do CTA.

A parede em frente à porta de entrada do CTA repleta de cartazes de eventos que o CTA fez parte, seja como organizador ou participante ("FISL16. $16^{\circ}$ Fórum Internacional de Software Livre. A tecnologia que libera", "3er Encuentro Latinoamericano de Tecnologias de Libre Acesso TECNOX 3.0”, "Maio das Tecnologias 
Livres! Em comemoração aos 6 anos do CTA, te convidamos para celebrar a lá hacker"') mostra que a ideia central discutida na reunião de fundação ainda permanece viva, mesmo passados seis anos.

Duda é mantenedor(a) da III Hackatona CTA - Relógio IF, importante projeto organizado pelo Centro. Embora as atividades sejam realizadas de maneira colaborativa um ou dois membros são designados para organizar cada atividade. Ele(a) "não é uma autoridade do projeto. É um(a) facilitador(a)" ${ }^{14}$ No evento organizado por Duda os(as) participantes estão projetando e construindo um relógio, que será instalado no auditório do Instituto de Física da Universidade. Para os(as) colaboradores(as) o relógio que irão criar, prototipar e fabricar não é somente um objeto, mas sim um hiperobjeto, quer dizer "[...] um objeto que foi criado com ferramentas livres, pode ser utilizado com software livre e sua documentação é livre" (PEZZI, et al., 2017, p. 213).

Uma das principais incumbências de Duda é fazer com que os(as) participantes do evento documentem todos os passos do projeto no site do Centro de Tecnologia Acadêmica. A página já está no ar e lá estão disponíveis arquivos editáveis, códigos-fonte, diagramas esquemáticos e links para repositórios, bem como a descrição de como as etapas do projeto estão sendo realizadas. Essa prática permite que pessoas interessadas em desenvolver projetos semelhantes tenham acesso aos erros e acertos do projeto em detalhe. Diante disso o novo projeto pode ser desenvolvido de maneira mais fácil e rápida, poupando o que chamam de "retrabalho".

A primeira etapa do evento já ocorreu. Os esforços agora estão voltados para a avaliação dela e para o planejamento da segunda etapa. Duda lembra que deve convocar uma reunião. Essa prática permite que tudo seja discutido com os(as) demais desenvolvedores(as) do evento. Antes de definir a data envia uma mensagem, via Telegram, ${ }^{15}$ para o grupo de organizadores.

"Pessoal, acho que deveríamos marcar uma reunião para definir encaminhamentos do evento. Compras para a segunda etapa. Divulgação da primeira etapa: notícia. Balanço geral da primeira etapa. O que aprendemos com esse evento? Podemos fazer a reunião no mesmo dia da semana passada? Quinta às $15 \mathrm{~h}$, quem pode?".

Em poucos minutos as repostas começam a chegar

Marcos: "não sei se poderei na quinta. Acho que não."

Carla: "não posso quinta nem sexta:/ mas vejam aí sem mim. Estou ocupada com outro evento"

Rodrigo: "por mim ok."

Após algumas trocas de mensagens Duda se sente confortável e define a data:

"Pessoal reunião amanhã ((quinta-feira)) às 15h30."

Agora que já realizou essa tarefa precisa auxiliar na edição de um texto, 
que será publicado no site do CTA como parte da divulgação do evento.

No espaço anexo à sala principal existem alguns computadores disponíveis para o desenvolvimento das atividades de desenvolvimento dos Hiperobjetos: programação de códigos fonte, desenho de esquemáticos, desenvolvimento de design de objetos, prototipagem e documentação de projetos. Embora eles não sejam exclusivos de um colaborador específico, mas sim do grupo todo, usualmente cada membro utiliza sempre o mesmo $P C .{ }^{16}$ Isso torna o trabalho mais ágil. Duda se senta ao computador que está posicionado no canto da parede. É o que ele(a) costuma utilizar. Como o texto está sendo produzido em conjunto com outros(as) colaboradores(as), ele(a) acessa o link que a responsável por sua produção enviou. Ele está sendo escrito através de um Etherpad ${ }^{17}$ e consiste em uma notícia para promover a III Hackatona.

Em um dado momento, nas mensagens que trocam pelo chat, um dos colaboradores que permanecera responsável pela produção do cartaz envia um arquivo com a versão preliminar. Após a troca de algumas mensagens outro participante opina.

Marcos: "Eu acho legal que as divulgações do CTA sejam feitas com a própria fonte do logo. Isso dá uma identidade visual. Mas não sei se vocês têm essa fonte disponivel."

Inácio: "Interessante, nunca tinha pensado na fonte."

André: "Temos a fonte sim. Chama final frontier - é a fonte do Star Trek. Deve estar apontada no site do CTA, na parte de identidade visual. Mas a fonte não tem caracteres acentuados: o " $e$ " de Acadêmica foi feito a mão no logo."

Após essa breve troca de mensagens um dos participantes envia dois novos modelos de cartaz, com as ideias que foram sugeridas. A troca de mensagens segue:

Duda: "Bah curti as imagens."

Carla: "LINDO."

Marcos: "Pensei em apresentar vários cartazes com o logo do CTA (somente o triângulo) e algumas palavras chave e num rodapé menor teria Centro de Tecnologia Acadêmica - CTA UFRGS."

André: "Faz uns esboços aí..."

Marcos:18 "Vou tentar. Qual o programa que vocês usam?"

Duda: "Inkscape $e^{19 "}$

Inácio: "Inkscape acho que já serve"

Marcos: "Valeu." 
Depois de algumas mensagens trocadas via chat a criação do texto para a página e do cartaz de divulgação são finalizadas, mais uma tarefa já foi cumprida.

Já se aproxima do horário do almoço, outro colaborador entra apressado pela porta auxiliar do portão azul, abre a última gaveta de um velho arquivo de aço, deixa alguns objetos pessoais e pega outros. Os colaboradores mais atuantes e antigos do CTA possuem a sua própria gaveta. Como são limitadas, há disputa por elas e quando um colaborador se afasta das atividades ele passa sua gaveta para um novato.

"Vai comer no RU?" ${ }^{20}$ pergunta o colaborador que havia entrado na sala.

Como Duda está com fome e já terminou uma tarefa, decide almoçar um pouco mais cedo do que de costume, pois no início da tarde terá aula na disciplina de Tecnologia de Vácuo e antes de retornar para casa voltará ao CTA para publicar a pauta da reunião desta semana no fórum dos encontros semanais, pois ficou com a incumbência de ser o(a) gestor(a) da próxima reunião.

No CTA os encontros semanais, que ocorrem presencialmente, são organizados por um(a) gestor(a), que é responsável por construir a pauta, conduzir a reunião, atentando-se aos tempos e falas. Além disso, deve elaborar uma ata que, após ser revisada pelos(as) presentes no final do encontro, é publicada imediatamente no site do CTA.

Quando sua aula termina, Duda retorna à sala L110. Lá estão alguns colaboradores que realizam atividades no laboratório. Um deles, utilizando máscara, óculos, luvas e um exaustor feito com dois coolers retirados de um computador inutilizado, solda componentes eletrônicos em uma placa de circuito impresso. Para tal utiliza a bancada que foi "improvisada permanentemente" sobre duas grandes caixas de som. Apesar de não ser rigorosa, a utilização dos equipamentos de segurança está descrita no Manual do CTA 21 "Não use furadeiras, solda, serra on faça outras atividades perigosas enquanto estiver sozinho no laboratório. Ao realizá-las, use equipamentos de seguranç".

Os outros trabalham de maneira colaborativa sentados em frente a um dos computadores disponíveis na sala anexa. Estão escrevendo um algoritmo para Arduino que será utilizado no projeto de um micro aerogerador que está em desenvolvimento.

O forte barulho vindo das máquinas do laboratório vizinho não atrapalha as atividades. Os(as) colaboradores(as) do CTA já estão acostumados e seguem normalmente como se o ruído não existisse.

Duda precisa tomar um café. Entre o arquivo de aço onde os colaboradores mais assíduos possuem suas gavetas há uma pequena mesa de madeira, que contém a cafeteira e algumas bolachas, ali está posicionado um tanque de fibra, desses utilizados para lavar roupa. No CTA ele serve como pia. É corriqueiro que os(as) colaboradores(as) passem várias horas na sala e precisem fazer algumas refeições ali mesmo. A água da torneira do tanque é utilizada apenas para lavar a louça. Um cartaz escrito em um pedaço de papel colocado acima da torneira alerta "Não beba desta torneira". Duda pega água de uma garrafa plástica. De tempos em tempos, os(as) colaboradores(as) precisam enchê-la no bebedouro localizado no corredor do prédio ao lado. 
Já discutiram em um encontro semanal sobre a limpeza do local. Alguns utilizam canecas, copos e talheres e não os mantêm limpos. Isso gerou certo conflito e os colaboradores se comprometeram a ser mais proativos na limpeza do espaço. Este tipo de "conflito" é sempre resolvido abertamente e com muita conversa. Todos os colaboradores se sentem à vontade para expor o que pensam, seja o assunto que for.

Assim que prepara o café, Duda senta em frente ao "seu computador". Faz o login no site do CTA; acessa o fórum "Encontros Periódicos" e clica na pauta do encontro da semana anterior. Analisa quais foram as pendências e a partir dai começa a elaborar a pauta do próximo encontro. Verifica se na lista de e-mails há sugestões de pauta.

Feito isso publica a pauta no site e depois envia um convite para a reunião na lista de e-mails "adm". ${ }^{22}$ Assim todos(as) os(as) inscritos(as) podem se atentar à data, hora, local do evento e assuntos que serão discutidos.

Já é hora de ir embora, mas quando está saindo, Duda vê que seus colegas irão utilizar a fresadora PCI João-de-Barro, uma máquina que cria trilhas em placas de circuito impresso. O equipamento é motivo de orgulho para os colaboradores do CTA, pois se trata de um Hardware Aberto e Livre (HAL), desenvolvido dentro do laboratório.

Por ser um HAL, qualquer pessoa pode fabricá-la sem infringir direitos de propriedade intelectual e as informações e procedimentos necessários para isso são encontrados facilmente na Wiki do projeto. Além do mais, os softwares necessários para sua operação são todos livres. Como consta na página do projeto sua mais importante característica é ser "Livre: a João-de-Barro é para todos". 23

A João-de-Barro, em conjunto com outras máquinas de fabricação digital, forma a infraestrutura ideal para o desenvolvimento dos hiperobjetos propostos pelo CTA. Denominada de bancada de hiperobjetos a estrutura é composta por um conjunto de máquinas de fabricação digital que possibilita a materialização dos hiperobjetos e por ferramentas digitais para desenho e simulação dos componentes de hardware.

Como tem pouca experiência na operação da João-de-Barro, Duda vê uma oportunidade de aprender um pouco mais. Junta-se aos colegas e começa a ouvir os diálogos. Um deles, Rodrigo, mais experiente na operação da fresadora, apenas tira dúvidas, enquanto o outro, Maurício, opera a máquina e explica seu funcionamento para dois novatos(as) que há pouco tempo se integraram às atividades do CTA.

Após alguns minutos de conversa e troca de experiências sobre a operação da fresadora, Maurício executa um comando que inicia o processo de fresagem da placa. Os dois novatos acompanham atentamente o funcionamento. Rodrigo e Maurício voltam a fazer outras tarefas.

Já é tarde, Duda precisa ir para casa. Lava sua caneca de café, pega sua mochila que estava sobre a mesa de reuniões, se despede dos(as) colegas e sai pelo portão do laboratório em direção à escadaria que leva ao ponto de ônibus.

Quando embarcar no ônibus que irá levá-lo(a) para casa, Duda encosta a cabeça na janela e descansa. Sabe que amanhã terá mais uma intensa jornada com atividades no CTA e aulas do sexto semestre do curso de Engenharia Física. 


\section{b. 0 CTA como uma CoP e as três dimensões da prática}

Nesta sessão discutimos separadamente cada uma das três dimensões que segundo Wenger (2001) permitem definir uma Comunidade de Prática. Para isso além de trechos do material coletado em campo também retomamos passagens da vinheta apresentada anteriormente e citações do referencial teórico.

\section{O Compromisso Mútuo e a convivência dentro do laboratório}

Os colaboradores do CTA não formam uma Comunidade de Prática somente pelo fato de reunirem-se semanalmente em encontros de mais ou menos uma hora na sala L110. A constituição do CTA como uma CoP se dá pelo fato de seus colaboradores cultivarem relações de participação mútua bastante intensas. Essas relações são sustentadas pela prática empregada para desenvolver seus projetos, compartilhando maneiras de realizar as suas atividades conjuntamente.

No trecho a seguir, retirado de uma reunião realizada para organizar a III Hackatona, um dos participantes explicava o que entendia por "atividade de nivelamento", planejada para ocorrer durante o evento:

"É falar sobre o gerenciamento de projetos, nossa interface de gestão, wiki. Metodologia de desenvolvimento de projetos. Nossa prática, como é que a gente far, como que o CTA funciona, nossas ferramentas. Vai conhecer o Inkscape, vai conbecer o Tropos. ${ }^{24}$ Daqui um pouco a gente tá ensinando pra alguém como é que boota 25 o Tropos num Pen drive”. (André)

De acordo com Wenger (2001), a prática em uma CoP existe pelo fato de existirem pessoas que se relacionam de maneira mútua, com relações conflitantes ou harmoniosas. E filiar-se em uma CoP é uma questão de manter um compromisso mútuo em relação a ela e a seus participantes. Nesse sentido as práticas desenvolvidas no CTA, principalmente os projetos que privilegiam o trabalho colaborativo, não apenas possibilitam, mas também incentivam a formação e o desenvolvimento do compromisso mútuo.

"Fabricacão coletiva é uma das metodologias que a gente segue aqui. É, por exemplo, ab eu vou desenvolver uma placa e não existe nenbuma razão pra não chamar gente que queira aprender a usar a máquina, por exemplo, acompanhar o processo, sabe? O processo de desenvolvimento da gente também é aberto e receptivo às pessoas". (Fala de abertura da III Hackatona, proferida pelo gestor do evento)

Além disso, os colaboradores do CTA sabem como e com o que os outros colegas podem contribuir nas atividades realizadas dentro da comunidade. A seguir é descrito um diálogo ocorrido durante a operação da fresadora João-de-Barro, no episódio narrado na vinheta "Boas vindas, venham colaborar com o CTA".

Chamamos a atenção do leitor para os momentos em que um dos colaboradores, o menos experiente na operação da fresadora, recorre ao outro, mais experiente, para tirar dúvidas. Inicialmente o colaborador mais experiente não participava da operação da máquina. Ele estava em outro ponto do laboratório 
trabalhando em atividades de outro projeto. Quando ocorreu o seguinte diálogo. ${ }^{26}$ - Ô Rodrigo. Qual é a posição pra... pra trocar a ferramenta mesmo? - pergunta Maurício. - X 0, Y 195, Z 0 - responde Rodrigo.

- Y 195. Ab::.:. Ó tem um buraquinho aqui que a gente encaixa a ferramenta. Pra poder botar ela pra cima. Ó, dai a gente bota ela bem pra cima primeiro. Pega a chavezinha e aperta 0 parafusinho ali ó - fala Maurício orientando os(as) novatos(as) que acompanhavam o processo.

- Liberon as travas, agora en vou pegar a fresa que vai ser a primeira coisa... A placa já tá lá, vou pegar a fresa 0.5. ... É 0.5 essa aqui? Acho que não é 0.5. Ô Rodrigo. - interpelando novamente o colaborador mais experiente.

Rodrigo levanta-se, vai até o grupo e começa a auxiliar mais de perto.

- Tu tens que pegar uma fresa 0.3. A menor que tiver.

- Ah, 0.3 tá aqui. Tá. - fala Maurício pegando a fresa de dentro de uma pequena caixa.

- Não. Tu nunca começas pela fresa - alerta Rodrigo, percebendo que Maurício iria começar o procedimento de maneira equivocada.

- Sim, sim. É verdade, eu ia colocar a fresa - responde Maurício.

- Por isso que eles estão nessa ordem. - fala Rodrigo, mostrando a tela do computador.

- Tá meu. Vai furar esse negócio ou não? - pergunta impaciente um dos novatos que participava da atividade.

- Ab eu tô com medo de fazer uma bobagem. Tu te importas de acompanhar o processo? Sópra ver se tá tudo certo. - Maurício pergunta para Rodrigo.

Então, Rodrigo verifica os parâmetros que foram colocados no software e diz: - Ok, agora dá um Home. ${ }^{27}$

Maurício aciona o comando e a máquina começa a funcionar.

O interessante deste episódio é que o nome dos atores poderia simplesmente trocar de posição se trocássemos, também, a operação da João-deBarro pela alteração do código fonte do Tropos. Maurício é um colaborador que possui amplo domínio sobre o projeto do sistema operacional Tropos, enquanto Rodrigo domina amplamente o funcionamento da fresadora.

De acordo com Wenger (2001, p. 103) 
o compromisso mútuo não apenas implica nossa competência, mas também a dos demais. Baseia-se no que fazemos e no que sabemos, bem como na nossa capacidade de nos relacionar significativamente com o que não fazemos e o que não sabemos, isto é, com as contribuições e o conhecimento dos outros.

Neste sentido, os colaboradores do CTA, por fazerem parte de um grupo social onde as pessoas se ajudam mutuamente, compreendem que é mais importante saber como dar e receber ajuda do que saber de tudo.

Esse compromisso mútuo não significa, no entanto, que não existam conflitos e tensões. Quando Duda lava sua caneca de café antes de sair do laboratório, faz isso, pois pretende evitar uma situação conflituosa que já ocorrera outras vezes. E lava a caneca, pois em uma reunião semanal as pessoas que participam do CTA negociaram e decidiram se engajar mutuamente em torno do objetivo de manter o local limpo e agradável.

Finalizamos esta sessão com dois depoimentos de alunos(as) do CTA, que expressam de maneira clara o compromisso mútuo existente nas práticas do grupo.

"O CTA é uma comunidade, e envolver-se com ela faz com que desenvolvamos nossa perspectiva sobre a colaboração e convivio entre as pessoas seja num grupo de trabalho, trabalhando num espaço físico em comum ou interagindo remotamente." (Depoimento de um ex-aluno(a) do CTA Retirado do site do laboratório)

"[...] trabalhar em grupo, trabalhar em projetos, autonomia para gerir projetos, independência tecnológica, entre outras coisas que aprendi no CTA. Esses aprendizados vieram da convivência, estar em um meio que é repleto de pessoas trabalhando em seus projetos, e também dispostas a ajudar umas as outras." (Depoimento de um aluno(a) do CTA - Retirado do site do laboratório)

\section{O empreendimento conjunto: desenvolver e construir Hiperobjetos}

Wenger (2001, p. 105) define o empreendimento conjunto como uma dimensão que mantém a Comunidade de Prática unida. De acordo com o autor é um processo conjunto de negociação que retrata o compromisso mútuo dos participantes. Além disso, se trata de um processo definido pelos próprios participantes dentro do contexto sócio-histórico da comunidade sendo um processo inerente aos membros da CoP. Ainda, acrescenta o autor, não se trata simplesmente de um objetivo que o grupo estabelece, mas algo que cria relações de responsabilidade mútua entre os membros, o que acaba se convertendo em parte integrante das práticas da comunidade.

$\mathrm{O}$ nascimento do CTA já começa com um processo negociado. O grupo foi fundado em uma reunião composta por 16 participantes, entre eles professores e alunos da universidade. A seguir destaco um trecho da ata de fundação do CTA que reflete o empreendimento conjunto definido pelo grupo de participantes:

"Tendo como objetivo resgatar o papel da universidade como local de domínio e cultivo do saber bumano [...] o CTA busca o desenvolvimento de tecnologias livres/abertas, sujeitas às liberdades de uso, estudo, 
modificação e distribuição, garantindo autonomia no aprendizado e no uso dessas tecnologias." (Ata de fundação do CTA, 23 de maio de 2012, material retirado do site do CTA)

Porém, passados seis anos desde a fundação do Centro este empreendimento conjunto proposto em sua fundação se materializou e ainda se materializa em suas práticas?

Quando descrevemos, na vinheta o logotipo do CTA, formado por quatro triângulos representando as liberdades de uso das obras culturais livres, e os cartazes de eventos, colados na parede do laboratório, chamamos a atenção para o fato de que a ideia de desenvolvimento de tecnologias livres explícita na ata de fundação do grupo, ainda permanece evidente nas práticas realizadas ali.

Em um artigo de relato de experiência publicado por colaboradores(as) do grupo em maio de 2017, intitulado Desenvolvimento de tecnologia para ciência e educação fundamentado nos preceitos de liberdade do conhecimento: o caso do Centro de Tecnologia Acadêmica (PEZZI et al., 2017, p. 206, grifo do autor) os(as) autores(as) destacam:

\begin{abstract}
Acreditamos que a fim de suprir as necessidades atuais da humanidade, sem prejudicar as gerações futuras, é preciso que floresşa uma cultura de esclarecimento, colaboração e de continuidade do conhecimento. Isso está alinhado com movimentos ligados à cultura livre, como software livre, hardware aberto e livre, ciência aberta e educação aberta. Tais movimentos têm chegado ao meio acadêmico de forma relativamente isolada, com grupos alinhados em diferentes desses aspectos. A integração desses conceitos, suas ferramentas e seus métodos em plataformas científicas e educacionais é o desafio do Centro de Tecnologia Acadêmica do Instituto de Física da UFRGS (CTA IF/UFRGS)
\end{abstract}

Wenger (2001) destaca que o empreendimento conjunto não é caracterizado pelo fato de todos os membros de uma CoP acreditarem nas mesmas coisas e entrarem em acordo com relação a todos os assuntos, mas sim no sentido de ser negociado de maneira coletiva.

A seguir é reproduzida uma conversa retirada de um grupo no Telegram, onde os(as) colaboradores(as) que participavam da organização da III Hackatona discutiam os conceitos de Hardware Aberto e Livre (HAL) e de Hiperobjeto: ${ }^{28}$

Marcos: Pessoal, o relógio que estamos fabricando se enquadra no conceito de biperobjeto, de $\mathrm{HAL}$ ou de ambos?

Maurício: Sim, biperobjeto. Tem que ter documentação livre e ser fabricado com bardware e software livre.

Renato: A impressora a laser usada para queimar o acrílico é proprietária, provavelmente. ${ }^{29}$

Maurício: Ah. Sim verdade.

Renato: Mas essa não é uma parte vital para seu funcionamento e poderia ser feita em uma impressora 3D livre, então acho que não impede que seja considerada um biperobjeto. 
Maurício: é existe um limite que é meio turvo pra mim. Porque foi usado um computador pra fazer os desenhos no KiCad ${ }^{30}$ que também não é livre. Assim como as chaves de fenda, martelo...

Renato: A única discussão é se é biperobjeto, mas HAL com certeza é. Acho que o nivel de primazia na definição de hiperobjeto é o que temos para amadurecer. Critérios importantes podem ser ferramentas essenciais para a fabricaşão da tecnologia e limites da profundidade de abertura que temos em nivel social. Nesse sentido acho que computadores e microcontroladores poderiam ser descartados hoje em dia, pois não atingimos esse nivel de abertura ainda. É uma barreira tecnológica fundamentada em lobby e no modelo de dominio da tecnologia. O que é diferente de softwares, por exemplo. Portanto softwares deverm ser livres, o que é o caso.

Carla: Acho que essas ferramentas ((referindo-se a ferramentas como chave de fenda e martelo)) são de conhecimento geral, e não são exclusivas. E existem limites bem profundos como a língua. $O$ português é um conbecimento aberto? Disponivel publicamente? Sim. Quis demonstrar quão longe o entendimento de hiperobjeto pode ir, se quisermos problematizar.

Renato: Sim, tentei tražer um pouco isso. A reflexão pode ir tão longe quanto a microfabricação, conhecimento de idioma ou fundição de metal usado em ferramentas. Alguma dependência com algum tipo de conhecimento ou tecnologia com barreira é difícil não ter.

André: Minha opinião: hiperobjeto é transdisciplinar. A transdisciplinaridade reconhece os níveis de realidade. Então, algo será hiperobjeto para alguns e não será para outros, dependendo para o que olba. Tem partes abertas, que seguem os critérios de HAL, de biperobjetos. Tem partes que não, que são totalmente fechadas. Basicamente depende do olho de quem vê. No caso do relógio, eu diria que todo o trabalho da equipe, que está documentando o seu trabalbo, registrando o projeto, se refere a hiperobjeto. Agora, para quem quer estudar microeletrônica, os componentes são proprietários - não é hiperobjeto. Para o engenheiro químico que quer estudar polimeros, o acrílico azul ((material utilizado para fazer o logotipo do CTA)) não é hiperobjeto.

Renato: É uma maneira muito inteligente de definir. Pois não precisa definir o que é, mesmo que organicamente, deixa aberto ao observador, que é o mais natural e potencializa a autoria. É bem legal. E quebra com alguns paradigmas de definição de conceitos, o que é muito massa. Parabéns.

O conceito de hiperobjeto, criado pelo coordenador do laboratório, é central nas práticas realizadas pelo CTA. No entanto, como mostra o diálogo acima, mesmo os membros mais centrais da comunidade discordam em algum nível sobre o que é ou não um biperobjeto.

Isso não é propriamente um problema para essa Comunidade de Prática, pois como afirma Wenger (2001, p. 106, tradução nossa) "a compreensão que possuem de seu empreendimento e de seus efeitos nas suas vidas não necessariamente deve ser uniforme para que seja um produto coletivo".

Sendo assim, para que pudessem desenvolver seus hiperobjetos as pessoas que atuavam no CTA criaram sua própria prática, organizavam hackatonas abertas para que outras pessoas pudessem aprender e colaborar, tinham um rígido processo de documentação de projetos, se reuniam semanalmente para tratar de assuntos de interesse do grupo, disponibilizavam as atas de reuniões de maneira aberta para que os(as) ausentes possam se inteirar dos assuntos tratados. 
Nas palavras de um dos colaboradores:

O CTA, ele é:: pelo que eu percebo do CTA, ele é tipo uma ideia, uma filosofia, um jeito de viver en diria ... E é formado pelas pessoas que concordam com isso e que seguem isso e convergem tudo nesse espaço que a gente chama de CTA. E essa filosofia e esse modo de viver é pensando em tecnologias livres, software livre, hardware livre, ciência aberta, ciência cidadã. [...] ciência aberta, é toda pesquisa, todos os desenvolvimentos que são feitos aqui a gente faz, de forma aberta, documentada, que as pessoas podem usar, que seja livre, que tenham licenças permissivas, [...]. (Depoimento de um dos colaboradores durante a III Hackatona)

\section{O uso de um Repertório Compartilhado para o desenvolvimento de Hiperobjetos}

O engajamento mútuo que permite aos membros da comunidade participar do empreendimento conjunto gera o que Wenger (2001, p. 110, tradução nossa) chama de repertório compartilhado. Este recurso permite que a comunidade negocie significados e

Inclui rotinas, palavras, instrumentos, maneiras de fazer, relatos, gestos, símbolos, ações e conceitos produzidos ou adotados pela comunidade no curso de sua existência e que passaram a fazer parte de sua prática.

No diálogo descrito na vinheta narrativa quando é discutida a confecção dos materiais de divulgação, Marcos questiona: "qual o programa que vocês usam?". As respostas simultâneas de Duda e Inácio indicando o uso do Inkscape mostram que ele se trata de um instrumento comum, uma maneira de fazer as coisas dentro do CTA que já está muito bem consolidada. O uso desse tipo de software, aberto e livre, é representativo, pois reflete a adoção de um repertório compartilhado que lhes permite negociar significados. De maneira que, seja possível realizar o seu empreendimento conjunto, desenvolver hiperobjetos.

Outro processo que evidencia esta dimensão é a preocupação em documentar todas as etapas de desenvolvimento de seus projetos. De acordo com Wenger (2001, p. 110), o repertório compartilhado "combina aspectos coisificados e de participação". E é justamente isso que representa o processo de documentação de projetos, registro de manuais e de eventos no site do CTA.

Isto é bem retratado quando o gestor da III Hackatona explica aos participantes novatos a importância da documentação dos projetos: "através da documentação, a gente garante que ele ((o projeto)) possa ser estudado, modificado e as licenças ((abertas)) garantem isso".

Documentar um projeto, utilizando ações e instrumentos produzidos e/ou adotados pelo CTA (repertório compartilhado), mostra o caráter complementar da participação e da coisificação dentro da comunidade. Na realidade, esses conceitos estão intimamente ligados e um pode compensar a limitação do outro.

A participação compensa as limitações próprias da coisificação. Mesmo que tudo esteja devidamente documentado (sobre o projeto) invariavelmente os colaboradores recorrem à ajuda dos colegas mais experientes para comparar e enriquecer suas interpretações. Por outro lado, a coisificação também compensa 
as limitações da participação. Isso ocorre, por exemplo, quando a ata do encontro semanal é publicada no site ou quando todos os passos do desenvolvimento de um projeto são publicados em um repositório.

No entanto utilizar e criar um repertório compartilhado requer um ajuste fino entre participação e coisificação. Se o que predomina é a participação e não há preocupação com a documentação dos projetos pode redundar em material insuficiente para ancorar as especificidades de projetos mais complexos. Entretanto se predomina a coisificação e tudo se coisifica, mas não existe oportunidade para compartilhar experiências e negociar significados de maneira conjunta pode ser que não exista participação suficiente para gerar significados. Isso explica por que mesmo que o tutorial de operação da fresadora João-de-Barro esteja disponível seja preciso recorrer a alguém quando um problema aparece.

\section{CONSIDERAÇ̃̃ES FINAIS}

Diante do vasto material coletado, em parte mostrado aqui, e durante o estudo e da análise do material empírico à luz do referencial teórico, pudemos caracterizar o CTA como uma Comunidade de Prática em pleno funcionamento.

Após a longa estada no CTA podemos descrevê-lo como sendo um grupo de pessoas que se engajam mutuamente em desenhar, projetar, desenvolver e empreender projetos de maneira colaborativa, guiados pelos princípios da ciência aberta, reificados na figura do hiperobjeto. E para isso fazem uso de um repertório compartilhado de técnicas, ferramentas, linguagem e ações que lhes permitem aprender, negociando significados na prática, construindo e desconstruindo suas identidades e a identidade do próprio CTA.

Este estudo detalhou o retrato cultural, algumas práticas e os processos de aprendizagem que ocorrem dentro de um grupo configurado como uma Comunidade de Prática capaz de abrir possibilidades para que os estudantes construam relações sociais complexas e tenham experiências de participação que: (i) exijam compromisso mútuo, tanto entre os estudantes como com outras pessoas envolvidas; (ii) apresentem desafios que solicitam os conhecimentos dos estudantes sem deixar de lhes encorajar a explorar novos territórios e (iii) desenvolvam práticas compartilhadas e um compromisso com o empreendimento e com os outros. Tal modelo, baseado no desenvolvimento de projetos colaborativos, contextualizados e situados histórica e socialmente, tem a potencialidade de auxiliar as instituições de ensino na promoção de práticas educativas capazes de desenvolver as habilidades necessárias para a formação do cidadão atual.

Visto como um espaço não-formal de aprendizagem esse tipo de Comunidade de Prática se mostra uma iniciativa, capaz de complementar o aprendizado de sala de aula. Esses ambientes, além de não afetarem a carga horária, já sobrecarregada pelos currículos escolares, podem oportunizar espaço e suporte para o aprofundamento da curiosidade, a divulgação das implicações cientificas no cotidiano, o estímulo ao trabalho coletivo e colaborativo e o desenvolvimento de uma postura inquiridora por parte dos alunos. Além disso, os alunos se filiam aos espaços não-formais de aprendizagem de maneira intencional, levados a participar 
das práticas e ações por um interesse próprio o que lhes permite aprender e trocar saberes de uma maneira distinta da que ocorre dentro das salas de aula.

Por fim, consideramos que a descrição detalhada do Centro de Tecnologia Acadêmica e sua caracterização como uma Comunidade de Prática realizadas neste trabalho abrem espaço para estudos futuros, que culminem em diretrizes para o fomento e cultivo deste tipo de iniciativa em ambientes escolares.

\section{AGRADECIMENTOS}

O presente trabalho foi realizado com apoio da Coordenação de Aperfeiçoamento de Pessoal de Nível Superior - Brasil (CAPES) - Código de Financiamento 001. Ives Solano Araujo agradece ao CNPq pela bolsa de Produtividade em Pesquisa. Agradecemos aos colaboradores do Centro de Tecnologia Acadêmica que foram participantes da pesquisa.

\section{REFERÊNCIAS}

ANGROSINO, M. Etnografia e observação participante. Porto Alegre: Artmed Editora S. A., 2009.

BINKLEY, M. et al. Defining Twenty-First Century Skills. In: GRIFFIN, P.; MCGAW, B.; CARE, E. Assessment and Teaching of 21st Century Skills. Dordrecht: springer, 2012. p. 17-66. DOI: https://www.springer.com/la/book/9789400723238

CASTRO, F. R. Há sentido na Educação Não Formal na perspectiva da Formação Integral? Museologia \& Interdisciplinaridade, Brasília, v. IV, n. 8, p. 171-184, dez. 2015. Disponível em $<$ http://periodicos.unb.br/index.php/museologia/article/view/17166>. Acesso em: 28 abr. 2020.

CRESWELL, J. Investigação Qualitativa e projeto de pesquisa. $3^{\circ}$. ed. Porto Alegre: Penso, 2014.

FETTERMAN, D. M. Ethnography: Step-by-step. $3^{a}$ Ed. Thousand Oaks: SAGE Publications Ltd., 2010.

GOHN, M. G. Educação Não Formal nas Instituições Sociais. Revista do Programa de Pósgraduação em Educação da Unochapecó, Chapecó, v. 18, n. 39, p. 59-75, set./dez. 2016. DOI: http://dx.doi.org/10.22196/rp.v18i39.3615.

LAVE, J.; WENGER, E. Situated Learning legitimate peripheral participation. New York: Cambridge University Press, 1991.

MILES, M. B.; HUBERMAN, A. M. Qualitative Data Analysis. London: [s.n.], 1994.

MOREIRA, M. A. Grandes desafios para o ensino de física na educação contemporânea, Brasília, v. 1, n. 1, 2017. Disponível em: <https://www.if.ufrj.br/ pef/aulas_seminarios/ seminarios/2014_Moreira_DesafiosEnsinoFisica.pdf>. Acesso em: 28 de abr. de 2020. 
PEZZI, R. et al. Desenvolvimento de tecnologia para ciência e educação fundamentado nos preceitos de liberdade do conhecimento: o caso do Centro de Tecnologia Acadêmica. Liinc em Revista, Rio de Janeiro, v. 13, n. 1, p. 205-222, Mai 2017. Disponível em: <http://revista.ibict.br/liinc/article/ view/3757>. Acesso em: 28 de abril de 2020.

WENGER, E. Comunidades de Práctica: Aprendizaje, significado e identidad. Barcelona: Paidós, 2001.

WENGER, E.; MCDERMOTT, R.; SNYDER, W. Cultivating Communities of Practice. Massachusetts: Harvard Business School Press, 2002.

WENGER, E.; TRAYNER, B. Communities of practice a brief introduction. Wenger-Trayner, 2015. Disponível em: <http://wenger-trayner.com/wp-content/uploads/2015/04/07-Briefintroduction-to-communities-of-practice.pdf>. Acesso em: 28 abril 2020.

\section{NOTAS}

1 Comunidade de Prática é uma denominação cunhada por Jean Lave e Etienne Wenger, no famoso livro intitulado "Situated Learning legitimate peripheral participation", publicado em 1991. Posteriormente, tornou-se um dos conceitos centrais da Teoria Social de Aprendizagem proposta por Wenger em 1998 (WENGER, 2001).

2 Um exemplo é o desenvolvimento do sistema operacional Linux, o seu código fonte está disponível para qualquer pessoa utilizar, estudar, modificar e distribuir. Muitos programadores têm se envolvido nas melhorias do sistema e ajudado a fazer do Linux o sistema que é hoje.

3 Ata de fundação do CTA. Disponível em: <http://cta.if.ufrgs.br/projects/suporte-cta/wiki/ Ata_de_Funda\%C3\%A7\%C3\%A3o_CTA>. Acessada em: 28 abr. 2020.

4 <https://reprap.org/wiki/RepRap/pt>. Acesso em: 28 abr. 2020.

5 <http://cta.if.ufrgs.br/projects/estacao-meteorologica-modular/wiki/Wiki>. Acesso em: 28 abr. 2020 .

6 Para Creswell (2014), o acesso a um grupo pode requerer encontrar um ou mais indivíduos que irão permitir o acesso do pesquisador. Esses indivíduos são denominados de guardiões.

7 As Hackatonas são eventos que reúnem pessoas com o objetivo de desenvolver projetos, encontrar soluções tecnológicas, explorar códigos, sistemas lógicos e acima de tudo discutir ideias para o desenvolvimento de projetos. Elas podem durar horas, dias e até semanas. O termo é composto pela junção dos vocábulos hacker e maratona. Esse tipo de evento é utilizado para o início do desenvolvimento de alguns projetos dentro do CTA.

8 Arduino é uma placa de prototipagem eletrônica de código aberto. Surgido em 2005, o projeto inclui hardware e software livre e visa oferecer ferramentas adaptáveis e de baixo custo para a criação de projetos interativos em diversas áreas.

9 Segundo Miles e Huberman (1994) uma vinheta é uma descrição focalizada de uma série de eventos considerados representativos, típicos ou emblemáticos em estudo. Ela tem uma estrutura narrativa, parecida com uma história, que preserva o fluxo cronológico e que normalmente é limitada a um breve período de tempo, a um ou alguns atores chave, a um espaço limitado ou a todos os três. 
Centro de Tecnologia Acadêmica da UFRGS como comunidade de prática e possibilidade de criação de espaços não formais de aprendizagem: um estudo etnográfico

10 Tais discursos foram extraídos das transcrições de áudio e vídeo.

11 Linha do ônibus de transporte urbano de Porto Alegre que leva à UFRGS.

12 "Obras ou expressões que possam ser livremente estudadas, aplicadas, copiadas e/ou modificadas, por qualquer um, para qualquer finalidade”. Definição de Obras Culturais Livres. Disponível em: <https://freedomdefined.org/Definition/Pt>. Acesso em: 28 abr. 2020.

13 No CTA é utilizada a denominação “colaborador” para identificar os participantes dos projetos.

14 Guia do Iniciante, material destinado a instruir os colaboradores sobre o Modelo de Organização de Projetos do CTA. Disponível em < http://cta.if.ufrgs.br/projects/suporte-cta/wiki/Manual_do_ CTA>. Acesso em: 28 abr. 2020.

15 Serviço de mensagens instantâneas em que os clientes possuem código aberto.

16 Sigla de Personal Computer, termo utilizado para se referir a um computador.

17 Editor de texto colaborativo on-line.

18 Marcos é um colaborador que participa do CTA a pouco tempo.

19 Inkscape é um editor de gráficos vetoriais de código-fonte aberto semelhante ao Adobe Illustrator, Corel Draw, Freehand ou Xara X. O que diferencia o Inkscape é o uso nativo de Scalable Vector Graphics (SVG), em português Gráficos Vetoriais Escaláveis, um padrão aberto baseado em XML do consórcio W3C.

20 Restaurante Universitário, onde os alunos geralmente fazem suas refeições.

21 Disponível em < http://cta.if.ufrgs.br/projects/suporte-cta/wiki/Manual_do_CTA>. Acesso em: 28 abr. 2019.

22 Lista de e-mails geral do CTA. Qualquer interessado em receber informações sobre eventos, reuniões, anúncios e discussões em tópicos específicos pode realizar a inscrição na lista, mesmo não sendo colaborador do CTA.

23 Disponível em <http://cta.if.ufrgs.br/projects/fresadora-pci-joao-de-barro/wiki>. Acesso em: 28 abr. 2020.

24 O TropOS é um sistema operacional portátil, desenvolvido pelo CTA, compatível com uso em pen drive para facilitar atividades de ensino, pesquisa e extensão. Disponível em: < http://cta.if.ufrgs. br/projects/tropos/wiki/Wiki?>. Acesso em: 28 abr. 2020.

25 Em informática, booté o termo em inglês para o processo inicialização do computador durante o carregamento do sistema operacional quando a máquina é ligada.

26 Extraído de uma gravação em vídeo.

27 Home é o comando responsável por dar início ao funcionamento da fresadora.

28 Foram suprimidas algumas mensagens que não contribuíam para o entendimento do diálogo. Também foram reunidas mensagens que foram enviadas em sequência pelo mesmo interlocutor. 
29 No projeto do relógio os participantes desenvolveram o logotipo do CTA vazado em uma placa de acrílico. Pela dificuldade de realizar esse processo dentro do laboratório decidiram que fosse feito em uma empresa.

30 KiCad é um programa computacional de código aberto para projetos de circuitos integrados. Possui ferramentas para elaboração de estrutura de produtos, arte final e visualizações $3 \mathrm{D}$ da placa de circuito impresso e seus componentes. Disponível em: <https://pt.wikipedia.org/w/index. php?title=KiCad\&oldid $=51178767>$. Acesso em: 28 abr. 2020.

Submetido em 11/03/2019

Aprovado em 03/07/2020

\section{Contato:}

Daniel Farias Mega

Instituto Federal Catarinense (IFC)

Campus Concórdia

Rodovia SC $283 \cdot \mathrm{km} 17$

CEP 89.703-720 - Concórdia, SC - Brasil 